\title{
Trama dos Sonhos: infâncias, esperança e performance ${ }^{1}$
}

\author{
Trama de los sueños: infancias, esperanza y rendimento \\ Dream plot: childhood, hope and performance
}

\author{
Tatiani Müller Kohls ${ }^{2}$ \\ Felipe da Silva Martins ${ }^{3}$ \\ Denise Marcos Bussoletti ${ }^{4}$
}

\begin{abstract}
Resumo
Este trabalho visa uma reflexão sobre uma ação desenvolvida em escolas da rede pública de ensino na cidade de Pelotas/RS, denominada Trama dos Sonhos. A partir da performance realizada, refletimos sobre as infâncias e a esperança, alindo a experimentação artística e a práxis pedagógica. $\mathrm{O}$ discurso das crianças, que muitas vezes é marginalizado, e de um futuro incerto, nos mostra a esperança como forma de resistência. Tomamos a performance como possibilidade de uma proposta diferenciada que privilegia a narrativa pessoal e coletiva no espaço escolar. Assim, pensamos também na possibilidade de outras pedagogias que possam ser sensíveis a complexidade destas questões na contemporaneidade.
\end{abstract}

Palavras-Chave: Educação; Infâncias; Performance; Sonhos; Esperança.

\section{Resumen}

Este trabajo busca una reflexión sobre una acción desarrollada en escuelas de la red pública de enseñanza en la ciudad de Pelotas / RS, denominada Trama de los Sueños. A partir de la performance realizada, reflexionamos sobre las infancias y la esperanza, alindo la experimentación artística y la praxis pedagógica. El discurso de los niños, que muchas veces es marginado, y de un futuro incierto, nos muestra la esperanza como forma de resistencia. Tomamos la performance como posibilidad de una propuesta diferenciada que privilegia la narrativa personal y colectiva en el espacio escolar. Así, pensamos también en la posibilidad de otras pedagogías que puedan ser sensibles a la complejidad de estas cuestiones en la contemporaneidad.

Palabras claves: Educación; Infancias; Rendimiento; Sueños; Esperanza.

\begin{abstract}
This work aims at a reflection on an action developed in public schools in the city of Pelotas/RS, called Dream plot. From the performance realized, we reflect on childhood and hope, combining artistic experimentation and pedagogical praxis. Children's discourse which is often marginalized and an uncertain future, shows us hope as a form of resistance. We take performance as the possibility of a differentiated proposal that privileges personal and collective narrative in the school space. Thus, we also think about the possibility of other pedagogies that may be sensitive to the complexity of these issues in contemporary times.
\end{abstract}

Keywords: Education; Childhood; Performance; Dreams; Hope.

\footnotetext{
${ }^{1}$ Este trabalho faz parte da dissertação de mestrado, em andamento, de Tatiani Müller Kohls, no Curso de Mestrado em Educação, do Programa de Pós-Graduação em Educação (PPGE), da Universidade Federal de Pelotas (UFPEL).

${ }^{2}$ Mestre em Antropologia; Programa de Pós-Graduação em Antropologia da Universidade Federal de Pelotas; Pelotas, Rio Grande do Sul, Brasil; tatianimuller@gmail.com.

${ }^{3}$ Mestrando em Educação; Programa de Pós-Graduação em Educação da Universidade Federal de Pelotas; Pelotas, Rio Grande do Sul, Brasil; felipedasmartins @ hotmail.com.

${ }^{4}$ Doutora em Psicologia; Programa de Pós-Graduação em Educação da Universidade Federal de Pelotas; Pelotas. Pelotas, Rio Grande do Sul, Brasil; denisebussoletti@gmail.com.
} 


\section{Trama dos Sonhos}

A Trama dos Sonhos se constitui como uma ação que começou a ser desenvolvida através de um projeto de extensão e pesquisa denominado Dicionário dos Sonhos (KOHLS; BUSSOLETTI, 2016; KOHLS; VARGAS, 2017), vinculado ao Núcleo de Arte, Linguagem e Subjetividade (NALS), da Faculdade de Educação da Universidade Federal de Pelotas (UFPel). Assim, esse trabalho se constitui a partir dessas oficinas, realizadas em escolas de ensino fundamental, da rede pública de ensino da cidade de Pelotas-RS.

Cabe salientar que o NALS é um projeto de extensão que busca integrar pesquisa e ensino, aliando experimentação artística e práxis pedagógica. O núcleo desenvolve suas ações desde 2008 e possui como pressuposto a construção de conhecimentos nos marcos da educação do sensível. Nesta perspectiva, enfoca as estéticas periféricas e os novos sujeitos do discurso que pela arte possam emergir como porta-vozes da cultura, contribuindo para a descentralização das diferentes formas de poder letradas e apontando para um novo olhar sobre a realidade social (BUSSOLETTI, VARGAS, 2014; MARTINS; et al, 2016; KOHLS et al, 2016). Ao longo de nossas ações, visamos também, a possibilidade de pensar outras pedagogias que possam ser sensíveis a complexidade destas questões na contemporaneidade (BUSSOLETTI; VARGAS, 2012; 2013; 2014).

A proposta metodológica da Trama dos Sonhos surge como forma de aproximação com o universo infantil, visando pensar as infâncias através da alegoria (BENJAMIN 2013a; 2013b) dos sonhos articulado com o princípio da esperança (BLOCH, 2005) e considerando a poética como um dos eixos das gramáticas das culturas das infâncias e esta como crítica da cultura (BUSSOLETTI, 2007).

O conceito de trama que utilizamos pode ser compreendido através do entrecruzamento das histórias, das experiências, do sentido teórico e metodológico pelo qual essa proposta vai se desenvolvendo:

La trama representa un saber incluyente, un saber resultado de intercambios de estímulos y reacciones, de afectos y afectaciones, de entrelazamientos en que cada sujeito podrá incluir en su devenir encarnado sus propias categorias en relación a su experiência, a los atravessamientos teóricos, estéticos, éticos, afectivos, eróticos y emotivos, y dichas categorías son desarrolladas en la trama de la vida, en nuestro estar ligados a la experiencia social y personal, a las tecnoligías cognitivas, sociales, físico-químicas, biológicas y comunicacionales com las que convivimos (CANAL, 2011, p. 22).

A trama possibilita esse diálogo com as diferentes formas de conhecimentos e de intercâmbio entre as trocas que surgem com as crianças. É através de uma trama que se forma 
a partir das nossas histórias e sonhos que pretendemos apresentar as reflexões que emergiram a partir da confecção da "trama dos sonhos" e a relação entre infância, esperança e performance.

\title{
2. O outro com o qual se sonha...
}

\author{
Mas também aprendemos a esperar, pois o que uma criança deseja raramente chega \\ imediatamente. Sim, espera-se pelo próprio desejo, até que ele se torne mais claro. \\ Uma criança agarra tudo para encontrar o que tem em mente. Joga tudo fora, está \\ incessantemente curiosa e não sabe pelo quê. Mas o novo já vive aqui, o outro com o \\ qual se sonha (BLOCH, 2005, p. 29).
}

As crianças estavam dispostas em uma roda, após a apresentação de cada um dos integrantes, a instrução era de que na medida de sua vontade compartilhassem seus sonhos. Assim iniciamos a performance com uma integrante do grupo que segurando o novelo, se apresentou falando sobre seu sonho e ao terminar, segurou o fio do novelo e o jogou para a próxima pessoa se apresentar, assim todos participaram da performance. As crianças como já nos lembra a epígrafe de Bloch, "agarram tudo para encontrar o que se tem em mente" e segurando o fio do novelo, fomos nos encontrando com o Outro com o qual se sonha...

\author{
Ser professora \\ Cuidar do planeta \\ Poder ter poderes dos elementos \\ Me formar em educação \\ Ser veterinária \\ Meu sonho é não ter mais pesadelos \\ Ter uma boa vida \\ Formar na faculdade \\ Sonho em ter mais paciência \\ Morar em Santa Catarina \\ Viajar pro Canadá \\ Ir pro Rio de Janeiro \\ Ser policial \\ Visitar um lugar, ganhar presente \\ Morar em Pedro Osório \\ Me formar em medicina \\ Meu sonho é casar \\ Me formar em arquitetura \\ Ser cirurgiã \\ Ir pro Japão \\ Poder viajar em Paris \\ Ter poderes e poder ajudar todas as pessoas do planeta \\ Ir para a Disney \\ Ser médica e ajudar as pessoas
}


RELACult - Revista Latino-Americana de Estudos em Cultura e Sociedade

\author{
Ser veterinária \\ Ser dentista \\ Sonho ter irmãozinhos \\ Meu sonho é ser formiguinha \\ Ser bilionária e comer tudo do Krolow \\ Ser maquiadora \\ Meu sonho é desenhar \\ Ser doutora de animais \\ Que minha família dure bastante tempo \\ Ser inteligente \\ Ser uma artista \\ Meu sonho é ser uma borboleta.
}

Uma trama se forma, percebemos então, uma possibilidade de aproximação com o universo da infância. O discurso destas crianças, que muitas vezes é colocado como marginal, se torna a materialidade de um futuro incerto, e diante deste universo que nos é apresentado por essas crianças, concordamos com Benjamim pois,

[...] não tenho nada a dizer. Somente a mostrar. Não surrupiarei coisas valiosos nem me apropriarei de formulações espirituosas. Porém, os farrapos, os resíduos: não quero inventariá-los e sim faze-lhes justiça da única maneira possível: utilizando-os (BENJAMIM, 2006, p.502).

É nesta perspectiva de utilizar os farrapos e resíduos, que buscamos na fala das crianças sobre seus sonhos, a articulação entre a infância e a esperança, e tomamos a performance como meio, para que o sensível que emerge do fazer artístico, seja a melodia que nos guia. Percebemos na performance uma proposta diferenciada que privilegia a narrativa pessoal e coletiva no espaço escolar, onde nossas ações acontecem, pois,

Com efeito, a performance reenquadra todo o empreendimento educacional como um conjunto mutável e contínuo de narradores, histórias e performances, mais do que a simples e linear acumulação de competências disciplinares específicas e isoladas (PINEAU, 2010, p.97).

A performance, mesmo no espaço escolar, permite a experimentação de um espaço e tempo diferenciados, o que proporciona que os sentidos e significações se engendrem de outra forma (PEREIRA, 2012). Este olhar atento ao que a infância clama, nos tenciona a refletir na mesma direção de Miguel Arroyo (2012, p. 11), que destaca que Outras Pedagogias são inventadas na medida que outros educandos chegam ao espaço escolar, assim quando olhamos para as infâncias que nos interpelam com seus sonhos que vão desde "Ir pro Japão" até "Ter poderes e poder ajudar todas as pessoas do planeta", percebemos que a 
performance reconhece essas crianças "continuamente criando e recriando visões de mundo e suas posições contingentes dentro delas" (PINEAU,2010, p. 97), pela poética do fazer artístico, os sonhos compartilhados, não são somente sonhos individuais, mas as visões de mundo que estão sendo construídas naquele momento.

A partir da sociologia da infância (SARMENTO, 2004; 2005) podemos compreender que a criança é um ator social, que interroga a sociedade e constrói também a cultura em que está exposta:

As crianças, todas as crianças, transportam o peso da sociedade que os adultos lhes legam, mas fazem-no com a leveza da renovação e o sentido de que tudo é de novo possível. É por isso que o lugar da infância é um entre-lugar [...] o espaço intersticial entre dois modos - o que é consagrado pelos adultos e o que é reinventado nos mundos de vida das crianças - e entre dois tempos - o passado e o futuro. É um lugar, um entre-lugar (Bhabha, 1998) socialmente construído, mas existencialmente renovado pela acção colectiva das crianças. Mas um lugar, um entre-lugar, prédisposto nas suas possibilidades e constrangimentos pela História. É por isso um lugar na História (SARMENTO, 2004, p. 2-3).

Através de um "exercício de alteridade", buscando no "Outro" ou através do "Outro" novas significações ou ressignificações (BUSSOLETTI, 2007; 2011), compreendemos as crianças como produtores sociais e culturais, assim, olhamos para e com as infâncias em busca de um novo olhar que possa mostrar alternativas e "outras" formas de se fazer e pensar a Educação.

\section{A única esperança}

Ao término desse primeiro momento da performance, perguntamos às crianças o que havíamos construído com os fios. Como uma imagem síntese, uma das crianças afirmou que a trama de apresentações, feita com o novelo de lã, "representava nossos sonhos e que deveríamos segura-los até realizar". Ernst Bloch sobre o sonho diurno destaca que,

Todo sonho permanece sendo sonho pelo fato de ter tido muito pouco êxito, de ter conseguido levar pouca coisa a termo. Por isso, ele não pode esquecer o que falta, e mantém a porta aberta em relação a todas as coisas. A porta no mínio entreaberta, quando se dirige para objetos agradáveis, chama-se esperança (BLOCH, 2005, p. 326).

O sonho diurno ou acordado pode ser entendido como os planos futuros, uma visão utópica daquilo que desejamos, constituindo assim, uma consciência esperançosa do futuro (FURTER, 1974). No sonho acordado, a esperança se apresenta como uma expectativa da transformação, do desejo. 
Há sonhos diurnos em número suficiente, só não foram satisfatoriamente observados. Mesmo de olhos abertos, no seu íntimo a pessoa pode ver tudo colorido ou em forma de sonho. Se a propensão para melhorar aquilo em que nos tornamos não adormece nem durante o sono, como o poderia durante a vigília? Poucos são os desejos que não estão carregados de sonho, justamente quando eles tomam consciência de si. Mas, então, quem sonha durante o dia é visivelmente diferente de quem sonha durante a noite. Muitas vezes, quem devaneia segue um fogo-fátuo, desvia-se do caminho. Mas ele não dorme e não submerge na névoa (BLOCH, 2005, p. 80).

Nessa perspectiva, é a partir do sonho diurno que podemos pensar em uma experiência da esperança, quando o ser humano se lança para o futuro. Assim, as infâncias que se apresentam em contextos trágicos ou periféricos nos possibilitam a pensar a esperança que surge enquanto forma de resistência.

Essa esperança de segurar nossos sonhos até que eles se realizem, conclamada por essas crianças, um misto de angustia e esperança (BLOCH, 2005), se resume no que Walter Benjamim diz, “A única esperança seria uma Redenção (Erlösung) - ainda um conceito messiânico -, mas de onde virá? Dessa vez, a resposta é profana: a salvação virá das crianças [...]" (2013, p. 17). Desse modo, através de procedimentos performáticos almejamos acessar a [re]produção dos significados culturais do grupo ao qual aquelas crianças fazem parte, e ter acesso a visão de mundo destas. Compreendemos essa ação como uma possibilidade de acesso às gramáticas das culturas e representações infantis (SARMENTO, 2005).

\section{Considerações finais}

Evidenciamos aqui, como considerações finais, a importância de se buscar uma educação voltada para a diversidade cultural e social, e de adentrar no espaço real e imagético das experiências infantis, buscando nesse universo de possibilidades, não só de acessar o universo das crianças, suas representações, seus sonhos e esperanças, mas também como representam esse universo e as próprias situações que vivem e que estão expostas.

Destacamos ainda a importancia de se pensar em Outras possibilidades de se fazer e pensar a Educação, e o reconhecimento das crianças enquanto sujeitos que criam e recriam sua própria cultura. Assim, através do sonho diurno, desse sonho que nos move para o futuro, pensamos em como as infâncias podem mostrar uma outra história sobre a realidade em que vivem e assim, tomamos a Trama dos Sonhos como uma prática educativa que possa ser sensível, emancipadora e que as reconheça as crianças enquanto sujeitos e produtoras de conhecimento. 


\section{Referências}

ARROYO, M. Outros sujeitos, outras pedagogias. Petrópolis: Vozes, 2012.

BENJAMIN, WALTER. O capitalismo como religião. São Paulo: Boitempo, 2013. . Origem do drama trágico alemão. $2^{\mathrm{a}}$ Ed. Belo Horizonte: Autêntica, $2013 \mathrm{a}$. . Passagens. Trad. de Irene Aron. Belo Horizonte: Editora da UFMG, 2006. Rua de mão única - Infância berlinense: 1900. Belo Horizonte: Autêntica, 2013b.

BLOCH, E. O princípio da esperança. V.1. Rio de Janeiro: EdUERJ Contraponto, 2005.

BUSSOLETTI, D.M. Infâncias Monotônicas - Uma rapsódia da Esperança - Estudo psicossocial cultural crítico sobre as representações do outro na escrita de pesquisa. Porto Alegre, 2007. Tese (Doutorado em Psicologia) - Pontifícia Universidade Católica do Rio Grande do Sul.

BUSSOLETTI, Denise Marcos; GUARESCHI, Pedrinho Arcides. Infâncias Monotônicas: representações da alteridade na escrita de pesquisa. Práxis Educativa, Ponta Grossa, v. 6, n. 2, p. $303-313,2011$.

BUSSOLETTI, D. M.; VARGAS, V. Leituras em Dramaturgia Teatral para a Diversidade. Pelotas/RS: Editora e Gráfica Universitária UFPEL, 2012.

. Outras fronteiras em extensão. Revista Expressa Extensão, v. 18, n. 02, p.05-22, 2013.

Por entre fronteiras de uma pedagogia que pauta a educação pelas artes gingando saberes e práticas populares. Revista Extraprensa, v.01, n. 14, p. 41-48, 2014.

CANAL, Carlos Yáñez. El pluralismo de las ciencias sociales: Hacia la construcción de una trama de tramas. In: BUSSOLETTI, D. M.; CANAL, C. Y.; GUEVARA, A. E.; LANDÍN, D. M. (orgs). Pluralismo nas Ciências Sociais: da multiplicidade à diferença. Pelotas: Editora Universitária/UFPel, 2011.

FURTER, Pierre. Dialética da esperança. Rio de Janeiro: Paz e Terra, 1974.

KOHLS, T.M.; BARBOSA, R.D.; MARTINS, F.S; BUSSOLETTI, D.M. PET FRONTEIRAS - Saberes e Práticas Populares: uma proposta pautada na diversidade social e cultural. Conexões Culturais - Revista de Linguagens, Artes e Estudos em Cultura, v. 2, p. 48$55,2016$.

KOHLS, T.M.; BUSSOLETTI, D.M. Pensando as representações infantis através dos sonhos. XVIII ENPOS - Encontro de Pós-Graduação, 2016, Pelotas.

KOHLS, T.M.; VARGAS, V.; BUSSOLETTI, D.M. Dicionário das crianças: uma possibilidade de significados e representações de gênero no universo infantil. RELACultRevista Latino-Americana de Estudos em Cultura e Sociedade, v. 03 n 01, p. 17-25, 2017. 
MARTINS, F.S.; KOHLS, T. M.; BARBOSA, R.D.; MOREIRA, T.F.; BUSSOLETTI, D.M. Confraria do Fuxico - As tramas e os "Nós" junto ao PET FRONTEIRAS: Saberes e práticas populares. Conexões Culturais - Revista de Linguagens, Artes e Estudos em Cultura, v. 2, p. 39-47, 2016.

PEREIRA, M. D. A. Performance e educação: relações, significados e contextos de investigação. Educação em Revista, Belo Horizonte, v. 28, n. 1, p. 289-312, 2012. Disponível em: <http://dx.doi.org/10.1590/S0102-46982012000100013.>. Acesso em: 22 agosto 2017.

PINEAU, E.L. Nos Cruzamento Entre a Performance e a Pedagogia: uma revisão prospectiva. Educação \& Realidade, Belo Horizonte, v35, n. 2, p.89-114. Disponível em: 〈http://sochilewww.redalyc.org/articulo.oa?id=317227077007>

SARMENTO, Manuel Jacinto . As Culturas da Infância nas Encruzilhadas da Segunda Modernidade. In: Sarmento, M. e Cerisara, A. Crianças e Miúdos: perspectivas sociopedagógicas da infância e educação. Porto: Edições ASA, 2004.

Gerações e alteridade: interrogações a partir da sociologia da infância. Educação $e$ Sociedade, Campinas, vol. 26, n. 91, p. 361-378, 2005. 